Provided for non-commercial research and education use. Not for reproduction, distribution or commercial use.

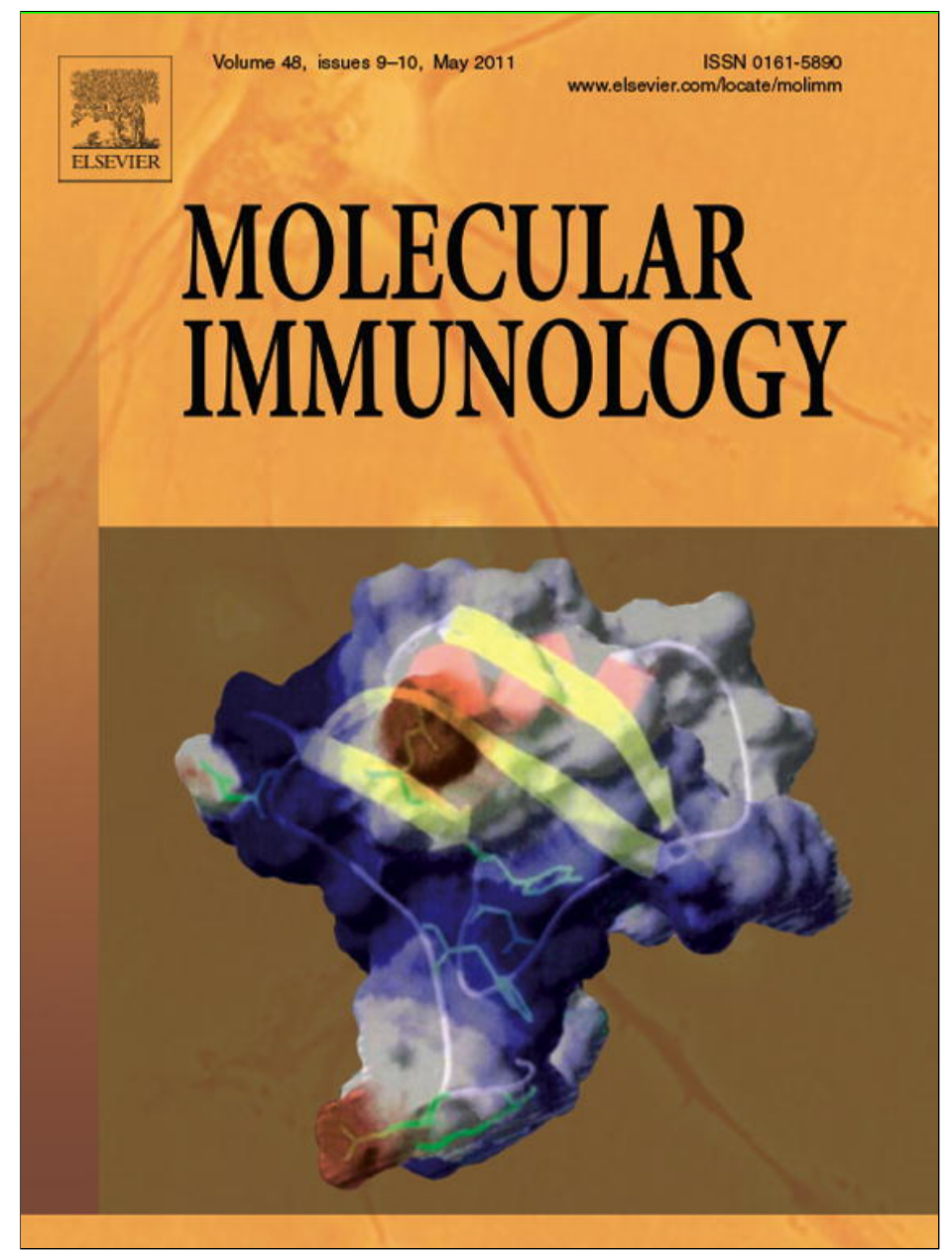

This article appeared in a journal published by Elsevier. The attached copy is furnished to the author for internal non-commercial research and education use, including for instruction at the authors institution and sharing with colleagues.

Other uses, including reproduction and distribution, or selling or licensing copies, or posting to personal, institutional or third party websites are prohibited.

In most cases authors are permitted to post their version of the article (e.g. in Word or Tex form) to their personal website or institutional repository. Authors requiring further information regarding Elsevier's archiving and manuscript policies are encouraged to visit:

http://www.elsevier.com/copyright 


\title{
Organisation and diversity of the class II DM region of the chicken MHC
}

\author{
Olympe Chazara ${ }^{\mathrm{a}, *}$, Michèle Tixier-Boichard ${ }^{\mathrm{a}}$, Véronique Morin ${ }^{\mathrm{b}}$, Rima Zoorob ${ }^{\mathrm{b}}$, Bertrand Bed'Hom ${ }^{\mathrm{a}}$ \\ a INRA, UMR 1313, Génétique Animale et Biologie Intégrative, Jouy-en-Josas, France \\ b CNRS, FRE 2937, Génétique Moléculaire et Intégration des Fonctions Cellulaires, Villejuif, France
}

\section{A R T I C L E I N F O}

\section{Article history:}

Received 11 February 2010

Received in revised form 20 February 2011

Accepted 14 March 2011

Available online 8 April 2011

\section{Keywords:}

Major histocompatibility complex

Gallus gallus

DM

Class II

Genetic diversity

\begin{abstract}
A B S T R A C T
In mammals, the DM molecules are encoded by the major histocompatibility complex (MHC) and execute key functions in the class II antigen presentation pathway. Here, we characterised three $D M$ genes in the MHC $B$ region of the chicken (Gallus gallus): B-DMA, B-DMB1 and B-DMB2. They encode one class II DM $\alpha$ chain and two $\beta$ chains, exhibiting motifs of chicken class II molecules as well as specificities of mammal DM proteins. We also studied the expression pattern of those three chicken $B$-DM genes; they are expressed in immune related tissues. Thus we provide the comprehensive description of the genomic sequence of a class II $\alpha$ gene in the chicken and a valuable description of $D M$ genes in a non-mammalian vertebrate, reinforcing the hypothesis of the existence of DM genes in the primordial MHC, as suggested by previous studies in mammals. We were also able to reconstruct 124 haplotypes corresponding to the $8.8 \mathrm{~kb} B$-DM region, in accordance with the 212 SNPs identified in 146 individuals representing a wide range of experimental, commercial, and local breeds from Europe, Asia and Africa, and three wild species of fowl. We also discovered a repeat inside the $B$-DMA second intron, making possible the design and the typing of a new marker for the chicken MHC, linked to the class II region. Therefore this study not only describes three DM genes in the chicken, it also provides an overview of MHC diversity in the chicken.
\end{abstract}

(C) 2011 Elsevier Ltd. All rights reserved.

\section{Introduction}

The DM loci, first described by Cho et al. (1991) in the mouse genome, and Kelly et al. (1991) in the human genome, are nonclassical MHC class II genes. In the chicken, the MHC is located on microchromosome 16 , and is organised in two genetically independent gene complexes, $B$ and $Y$. A number of B serotypes, distinguished by classical serological methods (Briles and Briles, 1987) or recently by molecular genotyping techniques (Fulton et al., 2006), are associated with strong differences in resistance or susceptibility to infectious diseases such as Marek's disease. The classical class II molecules of the chicken (BL) are, as for mammals, composed of two chains, $\alpha$ and $\beta$, generally expressed by B cells and macrophages. They present peptides, principally derived from exogenous molecules, to CD4+ T lymphocytes. In the chicken, three classical class II genes have been described so far, two encoding $\beta$ chains and one encoding an $\alpha$ chain in the $B$ region, along with at least one non-classical class II gene $(B-L B I I I)$ in the $Y$ region. The cDNA encoding the $\alpha$ chain has been described but not located in

\footnotetext{
* Corresponding author at: GABI, INRA, Domaine de Vilvert, 78352 Jouy en Josas, France. Tel.: +331346526 50; fax: +33134652933.

E-mail addresses: olympe.chazara@jouy.inra.fr, olympechazara@gmail.com (O. Chazara).
}

the genomic sequence of chromosome 16 , which is not completely characterised (Salomonsen et al., 2003).

In mammals, the DM molecules are involved in the formation of classical class II/peptide complexes, before their expression at the surface of the cell. It has been shown that without DM, these complexes are unstable, disrupting antigen presentation (Morris et al., 1994). In fact, classical class II molecules are assembled in the endoplasmic reticulum and stabilised by a third protein, the invariant chain. In endosomes, the invariant chain is cleaved by proteases, and a peptide from the invariant chain, CLIP, remains attached to the binding site of the classical class II molecule. In the presence of DM, CLIP is cleaved and replaced by antigenic peptides, which are derived from proteolysis of exogenous antigens (Sloan et al., 1995). DM also acts as a chaperone protein for classical class II molecules by protecting them from denaturation in acidic compartments. Finally, the DM molecule controls the loading of antigenic peptides by inducing the dissociation of the classical class II/peptide complex of low stability. Thus, only complexes of high stability can be presented on the surface of presenting cells (Kropshofer et al., 1999).

The assembly of the chicken genome, the first map of the $B$ region of the chicken MHC (Kaufman et al., 1999) and the extended recent map (Shiina et al., 2007), show, in the $B$ class II region, a segment for which in silico gene prediction and comparisons with mammals indicates the probable presence of two or three genes orthologous to genes characterised as DM in mammals. Ever since, 
it has been assumed that the MHC $B$ region of the chicken encoded non-classical class II genes, with only a preliminary promising study by Atkinson et al. (2001) whereas the intracellular localisation and oligomerisation of the invariant chain with classical class II molecules has been recently demonstrated in the chicken (Ye et al., 2009).

This study was initiated as a step towards improving the knowledge of the gene content of the $B$ region, in order to determine the individual contribution of genes to disease incidence. In this context, we characterised in detail the molecular organisation, structure, and pattern of expression of the predicted $D M$ non-classical class II genes of the chicken. As shown below, we demonstrate that three $D M$ genes do exist in the $B$ region of the MHC of the chicken. And, in order to assess genetic diversity of these key immune system genes, we also characterised for these genes, a large number of SNPs, and a new marker, from a wide range of experimental, commercial, local breeds and wild related species.

\section{Material and methods}

\subsection{The cDNA library and screening}

A set of $B-D M$ CDNA were isolated from a serotype $B^{13}$ spleen cDNA library in the pCDM8 vector (Bernot and Auffray, 1991). A clone (C.4.5.6), with high similarities to the mouse and human $D M B$ gene, had been previously identified by systematic sequencing of chicken MHC genomic libraries (constructed by subcloning the MHC cosmid clone C.4.5 in the pUC19 plasmid vector). The C.4.5.6 fragment was amplified using the GeneAmp PCR (PerkinElmer) kit, in a total volume of $20 \mu \mathrm{L}$ with $200 \mathrm{ng}$ of DNA from the cosmid subclone C.4.5.6 and $2 \mu \mathrm{L}$ of $10 \times$ PCR buffer $(10 \mathrm{mM}$ Tris $\mathrm{HCl}$ $\mathrm{pH} 8.3,50 \mathrm{mM} \mathrm{KCl}, 1.5 \mathrm{mM} \mathrm{MgCl}_{2}, 2 \mu \mathrm{L}$ each of $10 \mathrm{mM}$ dNTP, $0.5 \mu \mathrm{M}$ of each primer (M13 universal) and $1 \mathrm{U}$ of Taq polymerase). The cycling conditions were an initial denaturation step at $94{ }^{\circ} \mathrm{C}$ for $2 \mathrm{~min}$, followed by 30 cycles at $94^{\circ} \mathrm{C}$ for $1 \mathrm{~min}, 60^{\circ} \mathrm{C}$ for $30 \mathrm{~s}$ and $72^{\circ} \mathrm{C}$ for $1 \mathrm{~min}$ followed by a final extension step at $72^{\circ} \mathrm{C}$ for $7 \mathrm{~min}$. The fragment obtained, encompassing C.4.5.6, was then ${ }^{32} \mathrm{P}-$ labelled using the Multiprime DNA labelling system (Amersham Biosciences), and used as a probe to screen approximately 200,000 clones from the cDNA library. Six clones gave positive hybridisation signals, their nucleotide sequence was determined for both strands by sequencing, and submitted to GenBank under the accession numbers HM545127 to HM545132.

\subsection{Total RNA isolation}

Total RNA was prepared from tissues of White Leghorn chicks (serotype $\mathrm{B}^{12}$ ). The tissues were the following: brain, bursa, heart, lung, and spleen. Thirty milligrams of each tissue were disrupted for $4 \mathrm{~min}$ at $10-14,000 \mathrm{rpm}$ with an IKA yellowline Dl 18 dispenser. Total RNA was isolated using the RNeasy mini kit from Qiagen. A purification step was added after disruption by pipetting the clear supernatant into a Qiashredder column (Qiagen) and centrifuging at $14,000 \mathrm{rpm}$ for $5 \mathrm{~min}$. Then, the filtrate was used following the RNeasy protocol, including the optional on-column digestion with DNAse (Qiagen RNase-Free DNase). The RNA concentration was measured by UV spectrophotometry.

\subsection{Genomic DNA origin and extraction}

In the study for genetic polymorphism investigation, 129 animals were used from 47 different populations or lines of domestic chickens (Gallus gallus), including 29 populations of various origins and selection history from the European AVIANDIV project
(Supplementary Table 1). Detailed information on these populations was reported elsewhere (Hillel et al., 2003). Thirty-four wild Gallus $s p$. were also studied: 25 red Junglefowl (G. gallus), 5 grey Junglefowl (Gallus sonneratii) and 4 Sri Lanka Junglefowl (Gallus lafayetii). Nineteen out of the 25 red Junglefowl were also from the AVIANDIV project.

For the $\mathrm{B}^{12}, \mathrm{~B}^{13}$, and $\mathrm{B}^{19}$ inbred lines from INRA (Nouzilly, France, Miller et al., 2004), the Silkie chickens from the Livestock Research Institute (Sinhua, Taiwan), and the other wild Gallus sp. from a zoological park in Clères, France, high molecular weight genomic DNA were obtained from blood samples, as described by Chang et al., 2006.

For four additional lines from INRA, the immune response lines (I.R. lines kept in Nouzilly, France, serotypes $\mathrm{B}^{12}, \mathrm{~B}^{15}, \mathrm{~B}^{19}, \mathrm{~B}^{21}, \mathrm{~B}^{34}$, Minozzi et al., 2007), and six Taiwanese chicken populations (from NCHU, Taichung, Taiwan), crude DNA extractions were prepared from blood by mixing $2 \mu$ L of whole blood with $250 \mu$ L of lysis buffer ( $1 \mathrm{M} \mathrm{pH} 8$ Tris $1 \%, 1 \mathrm{M} \mathrm{MgCl}_{2}$ 0.1\%, $3 \mathrm{M} \mathrm{NaCl} 5 \%, 1 \%$ Sigma IGEPAL) before precipitation by centrifugation and incubation with $250 \mu \mathrm{L}$ of $\mathrm{NaOH}(0.2 \mathrm{M})$ at $65^{\circ} \mathrm{C}$ for at least $2 \mathrm{~h}$ followed by neutralisation with $250 \mu \mathrm{L}$ of Tris $(0.1 \mathrm{M})-\mathrm{HCl}(0.2 \mathrm{M})$.

For Benin, Cameroon, Côte d'Ivoire and Ghana samples, DNA were obtained from blood using the DNeasy Blood \& Tissue Kit from Qiagen at the Department of Animal Science, University of Ghana (Legon, Ghana).

\subsection{Molecular MHC characterisation of the samples}

Each animal has been genotyped at the MHC level by PCR amplification with the LEI0258 marker (McConnell et al., 1999; Fulton et al., 2006), and with a new marker also located in the chicken MHC, called GAB0001. Primers for the LEI0258 marker were LEI0258-F: CACGCAGCAGAACTTGGTAAGG forward and LEI0258R: AGCTGTGCTCAGTCCTCAGTGC reverse. Primers for the GAB0001 marker were designed with the Primer3 software (Rozen and Skaletsky, 2000), using the sequence information obtained during this study: GAB0001-F: CATTCCCCATTAACGCACTC forward and GAB0001-R: AGAGTGTTGGGGTAGCCGAG reverse. Duplexed amplifications were done in $10 \mu \mathrm{L}$ with $100 \mathrm{ng}$ of DNA, $1 \times$ of QIAGEN Multiplex PCR Kit and primer concentrations of $0.1 \mu \mathrm{M}$ and the following PCR cycle setup: $94^{\circ} \mathrm{C}$ for $15 \mathrm{~min}$, then 35 cycles at $94^{\circ} \mathrm{C}$ for $45 \mathrm{~s}, 60^{\circ} \mathrm{C}$ for $1 \mathrm{~min} 30 \mathrm{~s}, 72^{\circ} \mathrm{C}$ for $1 \mathrm{~min}$, with a final extension at $72^{\circ} \mathrm{C}$ for $15 \mathrm{~min}$. After a $1: 10$ dilution, the PCR products were loaded on an Applied 3730XL automated sequencer for electrophoresis and the results were analysed using Genemapper v3.7.

In order to get the real size of the marker LEI0258 amplified fragment, more than half (64\%) of the alleles were sequenced, directly for homozygotes or after separation of the two alleles on a $4 \%$ agarose gel, band cutting and purification with a QIAquick PCR Purification Kit from Qiagen. Sequencing was carried out by Eurofins MWG Operon, using their standard protocol for purified PCR products.

\subsection{5. $R T-P C R$}

Seven oligonucleotides were used in order to study the expression of the genes of the region (Supplementary Table 2, Fig. 1). They were designed using the chicken MHC genomic sequence reported by Shiina et al. (2007) (GenBank accession number AB268588) and verified by the program Primer3 (Rozen and Skaletsky, 2000).

The RT-PCR was carried out in two steps, following the Applera protocol for the GeneAmp RT-PCR kit. Approximately $1 \mu \mathrm{g}$ of total RNA was used with $4 \mu \mathrm{L}$ of $25 \mathrm{mM} \mathrm{MgCl}_{2}, 2 \mu \mathrm{L} 10 \times$ PCR buffer, $0.2 \mathrm{mM}$ of each dNTP, $2.5 \mu \mathrm{M}$ of oligodT (16), $20 \mathrm{U}$ of RNase inhibitor and $50 \mathrm{U}$ of MulV reverse transcriptase in a final volume of $20 \mu \mathrm{L}$. The amplification step was carried out by adding $2 \mu \mathrm{L}$ of $25 \mathrm{mM}$ 
$\mathrm{MgCl}_{2}, 4 \mu \mathrm{L}$ of $10 \times$ PCR buffer, $32.75 \mu \mathrm{L}$ of $\mathrm{H}_{2} \mathrm{O}, 100 \mathrm{ng}$ of each oligonucleotide and $1.25 \mathrm{U}$ of AmpliTaq DNA polymerase to $10 \mu \mathrm{L}$ of the cDNA products of step 1 in order to obtain a final volume of $50 \mu \mathrm{L}$. The following programmes were run on a thermal Mastercycler Gradient (Eppendorf) or a GeneAmp PCR System 2700 (Applied Biosystems): for the reverse transcription, $15 \mathrm{~min}$ at $42{ }^{\circ} \mathrm{C}, 5 \mathrm{~min}$ at $99^{\circ} \mathrm{C}$, and $5 \mathrm{~min}$ at $5^{\circ} \mathrm{C}$, and for the PCR amplification, $1 \mathrm{~min}$ $45 \mathrm{~s}$ at $95^{\circ} \mathrm{C}$, then 35 cycles with $15 \mathrm{~s}$ at $95^{\circ} \mathrm{C}, 30 \mathrm{~s}$ at $60^{\circ} \mathrm{C}$, and a final step of $7 \mathrm{~min}$ at $72^{\circ} \mathrm{C}$. The RT-PCR products were always checked on agarose gel containing ethidium bromide (BET). The gel was exposed to UV light to reveal the presence or absence of amplified fragments and in order to confirm their expected size.

\subsection{PCR and sequencing}

In order to resequence seven parts of the region, including the putative coding sequences, 14 primers were designed (Supplementary Table 2, Fig. 1) using Primer 3 (Rozen and Skaletsky, 2000). First, for 95 domestic chickens, amplifications of PCR fragment numbers 2-7, and their sequencing, were carried out at the "Centre National de Séquençage" (CNS, Evry, France) following their standard protocol, at an annealing temperature of $60^{\circ} \mathrm{C}$. Fragments were sequenced in the forward and reverse directions. Then, for the same 6 PCR fragments, failed samples were reamplified and resequenced in our laboratory. This was done for approximately $16 \%$ of the domestic chickens. At the same time, we amplified and sequenced the same 6 fragments for 34 additional wild Gallus sp. An additional PCR was also performed (numbered 1) on all 129 samples. All those PCR were conducted in $40 \mu \mathrm{L}$ total volumes with $200 \mathrm{ng}$ of DNA, $1 \times$ of Qiagen Master Mix and primer concentrations of $0.1 \mu \mathrm{M}$. Cycling parameters were $94^{\circ} \mathrm{C}$ for $15 \mathrm{~min}$, then 35 cycles of $94^{\circ} \mathrm{C}$ for $45 \mathrm{~s}, 60^{\circ} \mathrm{C}$ for $1 \mathrm{~min} 30 \mathrm{~s}, 72^{\circ} \mathrm{C}$ for $1 \mathrm{~min}$, with a final extension of $72^{\circ} \mathrm{C}$ for $15 \mathrm{~min}$. When amplification was not working, which happened especially for Asian domestic breeds, annealing temperature was decreased to $58^{\circ} \mathrm{C}$. PCR products were always checked on an agarose gel containing ethidium bromide. The gel was exposed to UV light in order to check the specificity and quality of the fragment obtained. Sequencing was carried out by Eurofins MWG Operon, using their standard protocol for purified PCR products.

\subsection{Identification of EST and repeats}

The ESTs (expressed sequence tags) corresponding to the studied region and already reported were searched by BLAST (Altschul et al., 1990) in the dbEST section of GenBank database from NCBI, using the genomic sequence of the chicken $\mathrm{MHC}$ reported by Shiina et al. (2007) as query sequence (AB268588). Sequences were then aligned against the chicken genome v2.1 assembly of May 2006 with the software EST2GENOME from the EMBOSS package (Rice et al., 2000). Another EMBOSS program, ETANDEM, was used with a threshold score of 20 and for repeat sizes ranging from 2 to 50 to identify tandem repeats in the same genomic sequence.

\subsection{Sequence and data analysis}

Sequence quality and variation analyses were carried out for the 129 individuals with NovoSNP (Weckx et al., 2005), and Pregap4 v1.5 and Gap4 v4.10 components of the Staden package (Staden et al., 2000). With NovoSNP, reports were obtained for SNPs characteristics and individual genotypes using the default parameters. Only the SNPs with high probability of being accurate were kept for further analyses (the NovoSNP score above or equal to 12). Then SNPs were manually confirmed and sample genotypes were manually edited by looking back at the chromatogram, using NovoSNP and the Staden contig editor, especially to check the consistency of heterozygote genotypes.

Individual genotypes were thus obtained for the 129 individuals and were completed using the 16 corresponding sequences available in GenBank (accession numbers AL023516 from Kaufman et al. (1999), AB268588 from Shiina et al. (2007) and AB426141 to AB426154 from Hosomichi et al. (2008)), and the matching genome sequence. These genotypes were then formatted as an input file for PHASE (Stephens et al., 2001) and it was run under the MR4 model with $\mathrm{R}$ being the recombination rate set at 0 , in order to infer haplotypes. Those parameters seemed the more relevant for this small region $(8.8 \mathrm{~kb})$. Then a NeighborNet network was constructed (Bryant and Moulton, 2004), in order to represent the haplotypes, using Splitstree version 4.10 (Huson and Bryant, 2006) with default parameters. This method combines the principle of the neighbor-joining and split decomposition techniques.

\subsection{Diversity and phylogenetic analysis}

The online tool SeqPHASE (Flot, 2010) was used to convert PHASE output files back into the FASTA format. The nucleotide sequences were aligned and translated, and non-synonymous to synonymous substitution ratios (dN/dS) were calculated by the Nei and Gojobori method (Nei and Gojobori, 1986) with the P-distance parameter, using MEGA 4 (Tamura et al., 2007). The standard errors were estimated by the bootstrap method (500 replicates). Maximum parsimony phylogeny was constructed from the protein alignments, also with MEGA 4, with default parameters and 1000 bootstrap replications. Consensus trees were obtained with a $65 \%$ cut-off value.

\section{Results}

\subsection{Genomic organisation of $B-D M A, B-D M B 1$ and $B-D M B 2$}

\subsection{1. $B-D M A$}

The alignment of the putative genomic sequence for the $B$ $D M A$ gene, the sequence of two cDNA clones we isolated from a $\mathrm{B}^{13}$ spleen cDNA library (GenBank accession numbers HM545127 and HM545128), and the different ESTs identified in the GenBank database, showed that this gene consist of four exons, respectively 127, 267, 282 and 239 bp long, with an alternative first exon, $65 \mathrm{bp}$ long (Fig. 1). The size of the second and third exons was conserved between human and chicken. On average, introns were shorter, which is usual for genes within the MHC of the chicken but surprisingly the second intron was larger in the chicken. This was due to the presence of 5-7 repeats of a 12 (YYCCACTGATGT) or a 14 (YCCCACYRAYGYRT) nucleotide motif. This is the repeat we used as a genetic marker and following the nomenclature, we named it GAB0001 (Fig. 1).

The nucleotide sequence, thus defined for $B-D M A$, encoded a peptide of 263 amino acids, encompassing a MHC-II $\alpha 1$ domain and an IgC1 $\alpha 2$ domain. Five cysteines, whose positions are conserved in all reported mammalian protein $\mathrm{DM} \alpha$, made two disulfide bridges possible, one in the $\alpha 1$ domain and one in the $\alpha 2$ domain. The only potential site of $\mathrm{N}$-glycosylation identified in the chicken, however, did not correspond to those of mammals (Fig. 2).

\subsection{2. $B-D M B 1$ and $B-D M B 2$}

The alignment of the putative genomic sequence for the $B-D M B 2$ gene, the sequence of the four isolated cDNA (GenBank accession numbers HM545129 to HM545132), and the different ESTs identified in the GenBank database defined six exons for $B-D M B 2$, respectively, 48, 282, 285, 120, 36 and 99 bp long. There seemed to be an alternative splicing of exons 3 and 4 for these genes as 


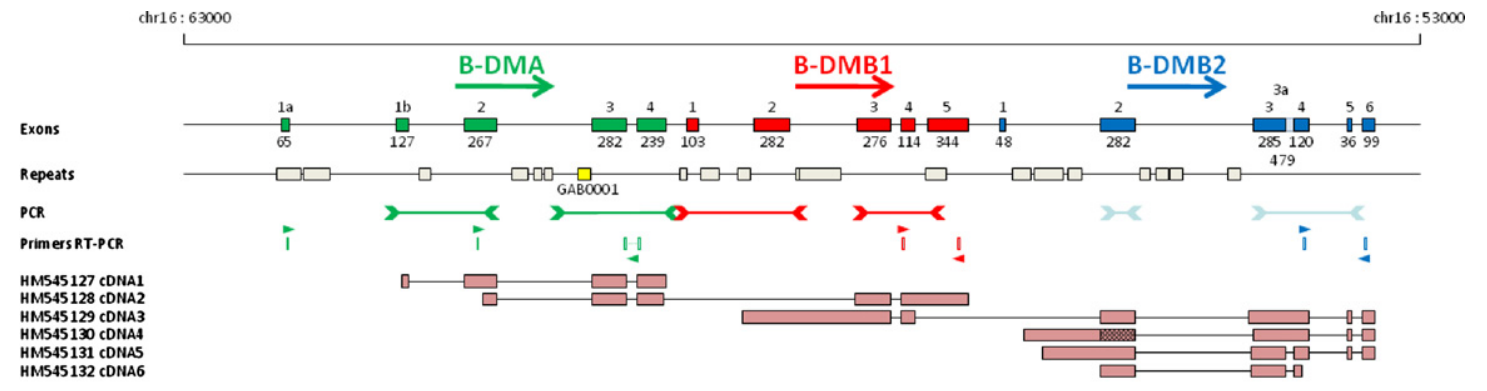

BU470717 ovary
BU472723 ovary

BU472723 ovary
CD738556 intestinal lymphocyte

BG711601 liver
CN233742 brain

CK615473 blood macrophages

CK613872 blood macrophages

CVo
BU112306 mixed tissues

BU1232658 kidney and adrenal
CK608011 blood macr ophages

CD732908 intestinal lymphocyte

AM0671421ymphold organs
AM1064678 Iymphoid organs

AM1064678 lymphoid organs
CK611700 blood macr ophages

BU299151 small intestine

BU397069 small in
BU3432456 brain

BU313246 brain
BU120557 brain

CD729587 intestinal lymphocyte

BOA 84750 macrophages
DN8S4341 mixed tissues

BM485663 mixedt tissues

BM487481 mixed tissues

$B 1392397$ brain
BU292829 small

UU291829 small intestin

CN232894 testis
BU281777 brain

DR427059 eye

BU455021 ovary
BOs85007 macrophages

C214996 maxedtissues

Al981726 activated T-cells

AMMO681431ymphoid organs

BU303895 small
BU413038 ovary
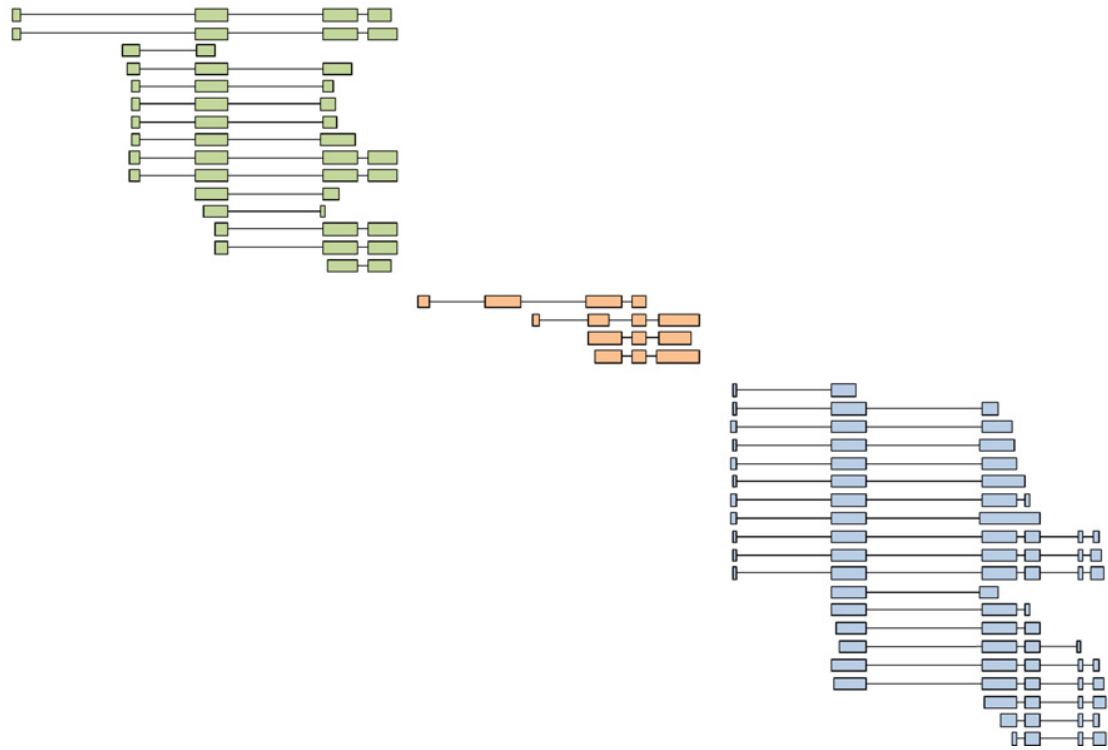

Fig. 1. $B-D M A, B-D M B 1$, and $B-D M B 2$, aligned with our six cDNA and 38 ESTs from the GenBank database, and the reversed corresponding $10 \mathrm{~kb}$ region of the chicken genome v2.1 assembly, of May 2006. Locations of the repeats are defined by grey boxes with the repeat used for the marker GAB0001 as a yellow box. Oligonucleotides used for PCR and RT-PCR are positioned respectively as linked arrows or boxes with pointers. A region of cDNA4 of lower sequence quality is indicated by shading.

observed for two cDNA and two ESTs (Fig. 1). This alternative splicing, however, induced a $2 \mathrm{bp}$ frame shift in the translated protein, leading to a premature stop codon.

Only part of two cDNA (GenBank accession numbers HM545128 and HM545129) and four ESTs in Genbank corresponded to the putative genomic sequence for $B-D M B 1$, none corresponding to a whole coding sequence. But they defined five exons being respectively 103, 282, 276, 114 and 344 bp long (Fig. 1).

The coding sequences, thus defined for $B-D M B 1$ and $B-D M B 2$, encoded for peptides of respectively 310 and 258 amino acids, comprising a MHC-II $\beta 1$ domain and an IgC1 $\beta 2$ domain. Six cysteines, whose positions are conserved in the majority of mammalian $\mathrm{DM} \beta$ proteins, made three disulphide bridges possible, two in domain $\beta 1$ and one in domain $\beta 2$. Respectively two and three potential $\mathrm{N}$ glycosylation sites were found in $B$-DM $\beta 1$ and $B$-DM $\beta 2$. Within the protein $B$-DM $\beta 2$ cytoplasmic tail, the mammal DM $\beta$ protein endosomal targeting signal YXXL was identified. This signal was not found in $B$-DM $\beta 1$ (Fig. 3).

\subsection{Genomic sequence features}

Putative promoters were found upstream of the first exons identified for $B$-DMA and $B-D M B 2$ : $\mathrm{X}$ and $\mathrm{Y}$ elements, typical of the class II promoter region (van den Elsen et al., 2004). These sites were similar to the promoters described for the HLA-DMA and HLA-DMB genes (Kelly et al., 1991; Westerheide et al., 1997), human class II A and $B$ genes, and chicken class II $B$ gene. The patterns and distances between them were conserved for the chicken $B-D M A$ and $B-D M B 2$ genes. No putative promoter could be found upstream of the $B-D M A$ alternative first exon. Finally, at the $3^{\prime}$ end of the three genes, we identified a TGA stop codon and an ATTAAA polyadenylation signal sequence (Supplementary Fig. $1 \mathrm{~A}-\mathrm{C}$ ).

The repeats identified in the region (Fig. 1) correspond mostly to intergenic or intronic sections, except for $B-D M A$ alternative first exon (numbered 1a), and $B$-DMB1 fifth exon (numbered 5). This reinforces the pseudo-exon status of the $B$-DMA exon and adds to the discussion of the $B-D M B 1$ gene organisation. One of the repeats identified within the $B$-DMA gene, within intron 2 (Fig. 1), was defined as the GAB0001 marker and was used to type the 95 domestic chickens of the study. Genotypes were obtained for 94 individuals (Supplementary Table 1). Five alleles were found: $144 \mathrm{bp}, 159 \mathrm{bp}, 161 \mathrm{bp}, 174 \mathrm{bp}$, and $187 \mathrm{bp}$. Duplex analyses of this marker and the LEI0258 marker was developed and led to the discrimination of animals sharing a common LEI0258 allele size, such as 261 bp (serology B2/B15) or 357 bp (serology B21/B23) (Supplementary Table 1).

\subsection{Expression of $B-D M A, B-D M B 1$ and $B-D M B 2$}

RT-PCR results indicated that mRNA of $B-D M A, B-D M B 1$, and $B$ $D M B 2$, are present in spleen tissues, even if no amplification was obtained for the primer corresponding to the alternative first exon of $B$-DMA. mRNA of $B$-DMA could also be amplified from brain and bursa tissues, and mRNA of $B-D M B 2$, from the brain, bursa and lung tissues. No amplification was obtained from heart tissues. The corresponding ESTs identified from the GenBank database provided additional information about the gene expression. ESTs corresponding to $B-D M A$ and $B$-DMB2 were identified in various tissues or cells (ovary, lymphocytes, liver, kidney, small intestine, macrophages, brain, lymphoid organs, testis, eye, and T cells), 

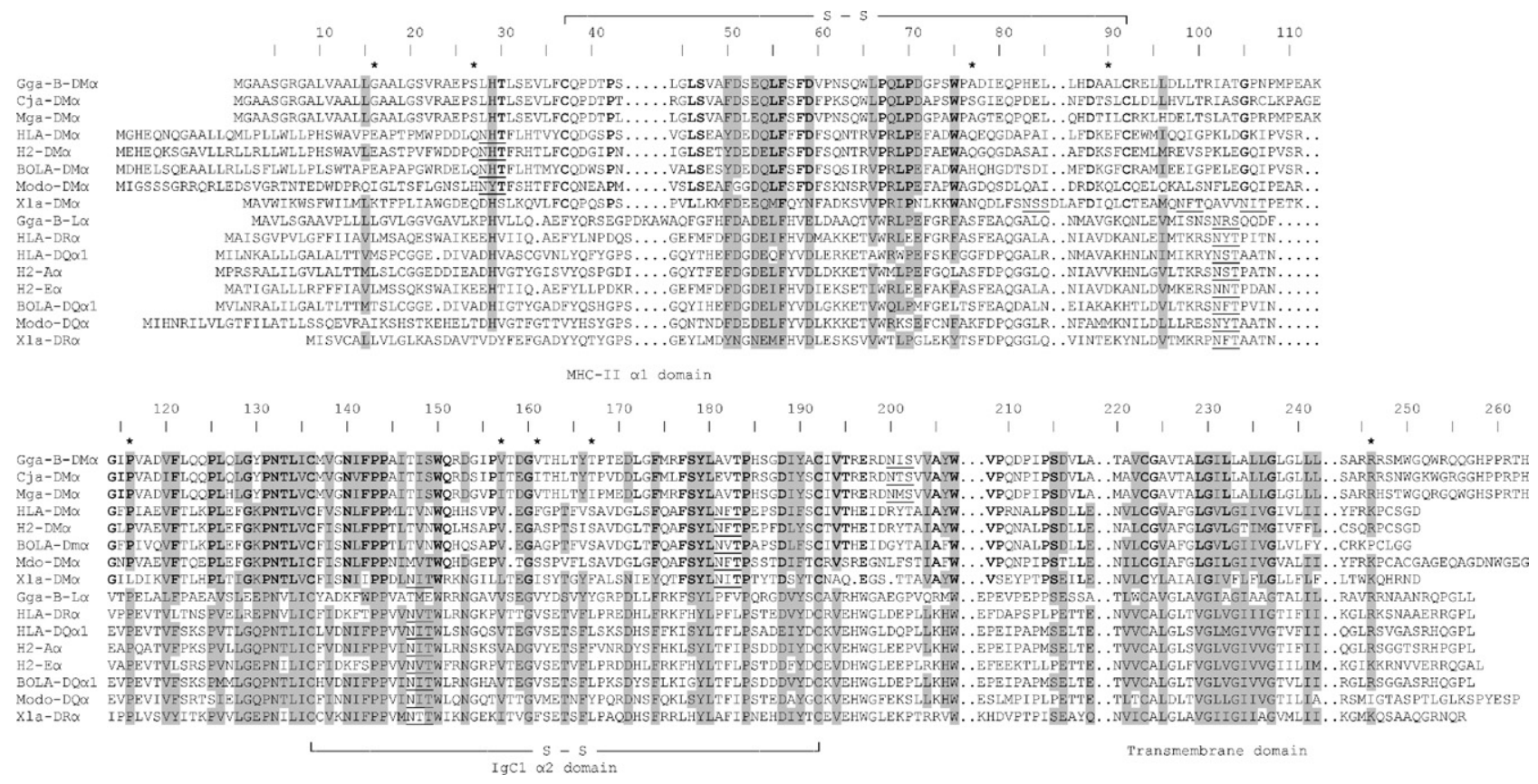

Transmembrane domain

Fig. 2. Alignment of the chicken Gga-B-DM $\alpha$ protein sequence with putative quail and turkey DM $\alpha$ sequence (Cja-DM $\alpha$, BAC82512, Mga-DM $\alpha$, ACA64775), sequences of mammalian proteins DM $\alpha(H L A-D M \alpha, H 2-D M \alpha, B O L A-D M \alpha$, Modo-DM $\alpha$, respectively: NP_006111, NP_034516, NP_001012692, and XP_001377359), putative frog DM $\alpha$ sequence (Xla-DM $\alpha$, NP_001083579), and sequences of Mhc class II $\alpha$ (chicken Gga-B-L $\alpha$, mammals' HLA-DR $\alpha, \mathrm{HLA}-\mathrm{DQ} \alpha 1, \mathrm{H} 2-\mathrm{A} \alpha$, H2-E $\alpha$, BOLA-DQ $\alpha$, Modo-DQ $\alpha$, respectively: AAY40299, NP_061984, NP_002113, NP_034508, NP_034511, NP_001013619, XP_001376932, and frog Xla-DR $\alpha$, NP_001090247). Gaps are indicated by dots. Similar amino acids at the same position are shaded in grey, with a 70\% threshold. Identical amino acids for the seven DM $\alpha$ proteins are in bold, excluding the sequence of the frog. Potential disulfide bridges are indicated by lines connecting two cysteines. Potential sites of N-glycosylation are underlined. Asterisks indicate variable positions in B-DM $\alpha$. Sequences are numbered according to the B-DM $\alpha$ protein.

unlike the four ESTs corresponding to $B$-DMB1, identified from only two tissues (small intestine and brain) (Fig. 1).

\subsection{Phylogeny analysis of the B-DM molecules}

We studied the relationship between the $\alpha 1, \alpha 2$ or $\beta 1, \beta 2$ protein domains of the three $B$-DM of the chicken, the three putative DM of the quail and the turkey, the two HLA-DM from humans, the three H2-DM from the mouse, the two BOLA-DM of the cow, the two Modo-DM of the opossum, the two putative DM of the frog, along with the classical class II proteins of the chicken and the above-mentioned animals. We found similar results whatever the domain analysed (data not shown). We always observed two clusters: a cluster grouping DM proteins and a cluster grouping class II proteins, as shown in the consensus parsimonious tree obtained for $\beta 2$ domains (Fig. 4).

\subsection{Genetic polymorphism of the B-DM molecules}

The analysis of the 7 PCR fragments obtained for 129 animals for $B-D M A, B-D M B 1$, and $B-D M B 2$, allowed the identification of 212 SNPs, from which 166 SNPs were polymorphic in domestic chickens (Supplementary Table 3). We identified 119 SNPs for $B-D M A$, 49 SNPs for $B-D M B 1$, and 44 SNPs for $B-D M B 2$. Concerning the coding regions, the distribution was the following: 32 SNPs in $B-D M A$, 31 SNPs in $B$-DMB1, and 30 SNPs in $B$-DMB2. In the alternative first exon of $B-D M A$, we found 3 SNPs in the 65 bp coding region, all non-synonymous. Due to a high rate of PCR failure for this 7th PCR fragment, comprising the alternative first exon of $B-D M A$, we did not use the genotypes of this fragment for the haplotype reconstruction.

The haplotype reconstruction, based on genotypes of the 146 individuals (129 domestic and wild animals plus 16 sequences available in GenBank and the genome sequence), at 158 SNPs, has led to the definition of 124 different haplotypes for the whole
$8.8 \mathrm{~kb} B-D M$ region. Detailed individual genotypes and haplotypes sequences are available upon request. The haplotypes were also inferred gene by gene, leading to the definition of 88 haplotypes for $B-D M A, 69$ haplotypes for $B-D M B 1$, and 71 haplotypes for $B$ DMB2. The complete haplotypes were combinations of the partial haplotypes, which is consistent with the hypothesis of a null recombination rate for the region. The removal of the wild Gallus sp. animals and their separate analysis for haplotype reconstruction did change the results neither for domestic nor for the wild chickens.

The NeighborNet network illustrates the relationships between the 124 haplotypes, representing 146 individuals (Fig. 5). We were able to group those haplotypes into 22 clusters, with two clusters, clusters 8 and 9 only represented by two haplotypes, which were not linked to any other cluster, even with different representation methods (data not shown). Even though some of the clusters, such as cluster 2 , are very compact, some clusters were subdivided into 2-4 groups, such as cluster 3 with $3 a$, 3b or cluster 14 with $14 a$, 14b, 14c, 14d (Supplementary Table 1). Only a few clusters could be linked to some characteristic of their corresponding samples. They are cluster 1, grouping haplotypes of African samples, cluster 2, grouping red Junglefowl haplotypes and cluster 21 grouping grey Junglefowl haplotypes. But the pattern drawn by the network indicated a stratification mostly based on MHC, not a stratification related to the breeds. So, interestingly, red Junglefowl haplotypes were scattered in the network.

There were 17 different serotypes represented in the study, by 43 homozygous animals. Their position in the network is indicated; they are linked to 12 clusters. Some serotypes were grouped together: $\mathrm{B}^{12}, \mathrm{~B}^{124}$ and $\mathrm{B}^{19}$, grouped in cluster $6, \mathrm{~B}^{4}$ and $\mathrm{B}^{13}$, grouped in cluster 15 , and $\mathrm{B}^{5}, \mathrm{~B}^{8}$, and $\mathrm{B}^{11}$, grouped in cluster 16 . Additionally, the haplotypes we obtained for animals defined by serology as $\mathrm{B}^{12}, \mathrm{~B}^{13}, \mathrm{~B}^{15}, \mathrm{~B}^{19}$, and $\mathrm{B}^{21}$, matched the haplotypes reported by Hosomichi et al. (2008) for animals of the respective serotypes (Supplementary Table 1). 

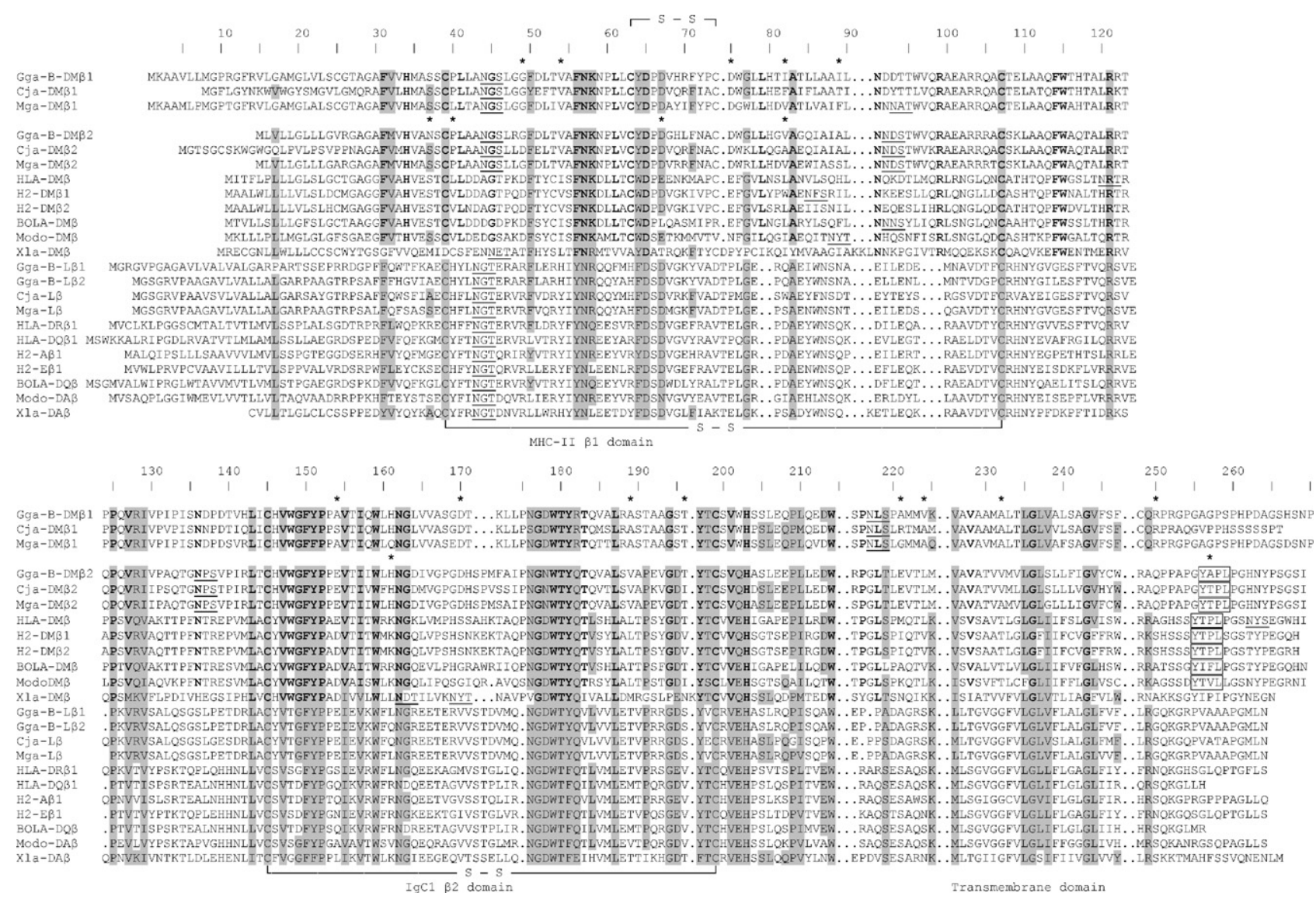

Fig. 3. Alignment of chicken protein sequences Gga- $B$-DM $\beta 1$ and Gga- $B$-DM $\beta 2$ with putative quail and turkey DM $\beta$ sequence $(C j a-D M \beta 1$, Cja-DM $\beta 2$, Mga-DM $\beta 1$, Mga$D M \beta 2$, respectively: BAC82513, BAC82514, ACA64776, ACA64777), with sequences of mammal DM $\beta$ proteins (HLA-DM $\beta, \mathrm{H} 2-\mathrm{DM} \beta 1, \mathrm{H} 2-\mathrm{DM} \beta 2, \mathrm{BOLA}-\mathrm{DM} \beta, \mathrm{Modo}-\mathrm{DM} \beta$, respectively: NP_002109, NP_034517, NP_034518, NP_001035571, and XP_001377337), putative frog DM $\beta$ sequence (Xla-DM $\beta, \underline{A B B 85336)}$, and sequences of Mhc class II $\beta$

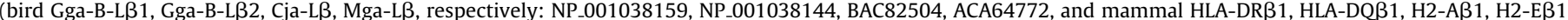
BOLA-DQ $\beta$, Modo-DA $\beta$, respectively: NP_002115, NP_002114, NP_996988, NP_034512, NP_001029840, NP_001028163, and frog Xla-DA $\beta$, BAA08759). Gaps are indicated by dots. Similar amino acids in the same position are shaded in grey, with a 70\% threshold. Identical amino acids for the eleven DM $\beta$ proteins are in bold, excluding the sequence of the frog. Potential disulfide bridges are indicated by lines connecting two cysteines, potential sites of $\mathrm{N}$-glycosylation are underlined. Potential endosomal addressing signals are framed. Gga- $B$-DM $\beta 1$ is truncated in 3'. Asterisks indicate variable positions in Gga- $B$-DM $\beta 1$ or in Gga- $B$-DM $\beta 2$. Sequences are numbered according to the Gga- $B$-DM $\beta 1$ protein.

Table 1

$\mathrm{dN} / \mathrm{dS}$ analysis of $B-D M A, B-D M B 1$, and $B-D M B 2$.

\begin{tabular}{|c|c|c|c|c|c|c|c|}
\hline Data $(n)$ & $\mathrm{nb} S$ & dS & S.E. & $\mathrm{nb} N \mathrm{~N}$ & $\mathrm{dN}$ & S.E. & $\mathrm{dN} / \mathrm{dS}$ \\
\hline$B-D M A(61)$ & 23 & 0.02003 & 0.00500 & 9 & 0.00168 & 0.00065 & 0.08387 \\
\hline$B$-DMA exon 2 & 13 & 0.04406 & 0.01425 & 3 & 0.00150 & 0.00094 & 0.03404 \\
\hline$B$-DMA exon 3 & 5 & 0.00847 & 0.00490 & 4 & 0.00188 & 0.00125 & 0.22196 \\
\hline B-DMB1 (58) & 18 & 0.02498 & 0.00666 & 13 & 0.00377 & 0.00128 & 0.15092 \\
\hline$B-D M B 1$ exon 2 & 7 & 0.01773 & 0.00808 & 5 & 0.00306 & 0.00178 & 0.17259 \\
\hline$B-D M B 1$ exon 3 & 9 & 0.03504 & 0.01511 & 4 & 0.00148 & 0.00078 & 0.04224 \\
\hline B-DMB2 (62) & 24 & 0.02631 & 0.00595 & 6 & 0.00125 & 0.00062 & 0.04751 \\
\hline$B-D M B 2$ exon 2 & 7 & 0.01210 & 0.00527 & 4 & 0.00195 & 0.00121 & 0.16116 \\
\hline$B-D M B 2$ exon 3 & 12 & 0.04432 & 0.01453 & 1 & 0.00075 & 0.00070 & 0.01692 \\
\hline
\end{tabular}

Values for the total sequence are in bold. $n$, Number of sequences analysed; nb S, number of synonymous SNPs; S.E., standard error; nb NS, number of non-synonymous SNPs.

Finally, we were also able to compare heterozygosity at the $B$-DM level with heterozygosity at the LEI0258 marker level (Supplementary Table 1). Six animals were homozygotes for the LEI0258 marker but heterozygotes concerning $B$-DM haplotypes but in each case, the two $B$-DM haplotypes were grouped in the same cluster and sub-group. There were also two animals, homozygote for $B$-DM haplotypes but heterozygote for the LEI0258 marker, so in total, the heterozygosity matched between the $B-D M$ region and LEI0258 for 139 of the 147 cases (95\%).

Using the same 124 reconstructed haplotypes, we were also able to predict the consequences on the $B$-DM proteins of the 28 non-synonymous SNPs. The non-synonymous SNPs in B-DMA led to nine amino-acid variations (genome residue-position-alternative residue): G-16-W, S-27-L, A-77-T, A-90-T, P-116-L, V-157-I, V-161-I, T-167-I, and R-246-Q (Fig. 2). The non-synonymous SNPs in B-DMB1 led to 13 amino-acid variations: G-49-S, V-54-M, D-75-N, I-82-V, I-89-V, A-154-T, D-170-E, A-189-V, T-196-A, A-221-V, V-224-M, A-232-V, and R-250-W (Fig. 3). The nonsynonymous SNPs in $B-D M B 2$ led to six amino-acid variations: N-23-S, P-26-S, D-53-N, V-68-M, H-147-R, and A-246-T(Fig. 3). Predicting the consequences of amino-acid variations for those chicken proteins was difficult, in relation with a lack of the suited 


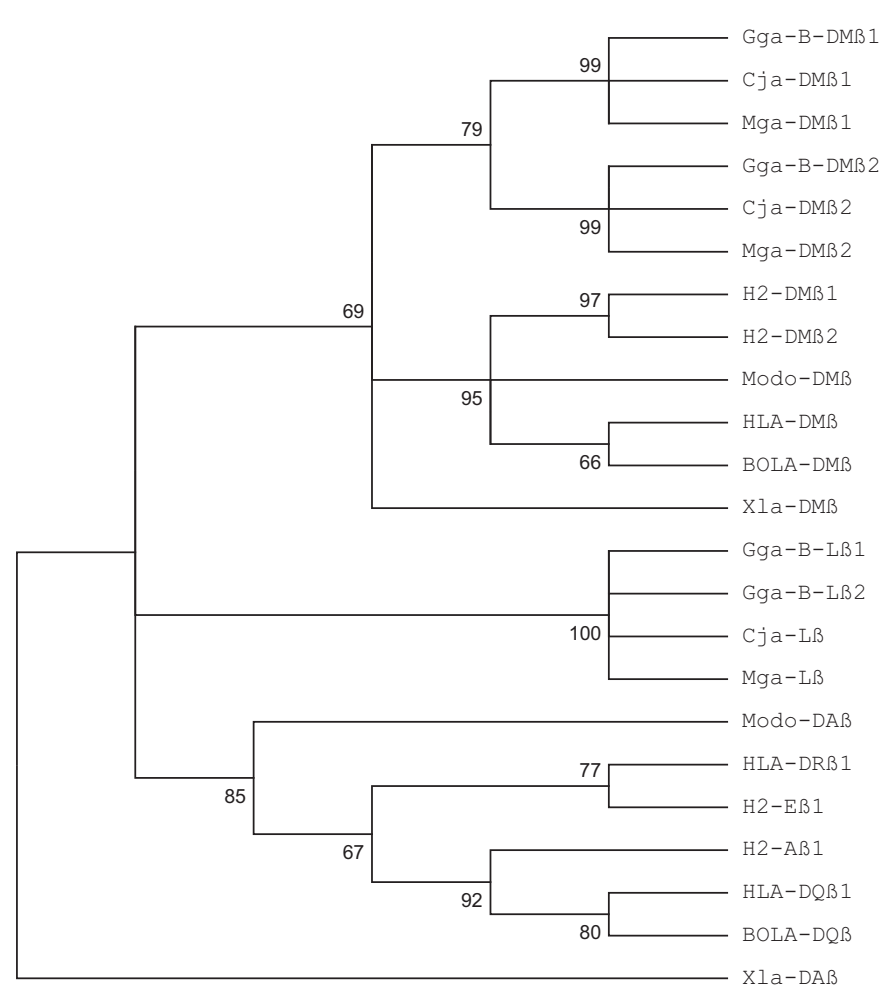

Fig. 4. Bootstrap consensus tree for the DM and classical class II $\beta 2$ domains, derived from the alignment Fig. 3. The percentages indicated are based on the 1000 bootstrap replicates.

predictive tools. Only a few substitutions seemed to affect a conserved residue and they were conservative.

Those amino-acid variations defined 12 non-synonymous alleles for $B-D M A, 22$ for $B-D M B 1$, and 8 for $B-D M B 2$. The $\mathrm{dN} / \mathrm{dS}$ analysis (Table 1) confirmed that $B-D M B 1$ is more polymorphic than $B$ $D M A$ and $B-D M B 2$. The two $B-D M B$ genes, however, showed both a higher diversification of the second exon, encoding the $\beta 1$ domain, whereas the $B-D M A$ gene showed a higher diversification of the third exon, encoding the $\alpha 2$ domain.

\section{Discussion}

\subsection{Genomic organisation of $B-D M A, B-D M B 1$ and $B-D M B 2$}

Structurally, the $B-D M$ genes have the features of MHC class II genes, plus potential additional disulfide bridges in their $\alpha 1$ or $\beta 1$ domains. It is noteworthy that the amino-acid sequence of the $B-D M B 1$ gene lacks a putative endosomal targeting signal, so its function could be different from the mammal $D M$ classic function. Interestingly, putative DMB1 genes found in the quail and turkey also lack this signal. We also found a higher rate of non-synonymous SNP in $B-D M B 1$, a more restricted expression, and we were unable to find a cDNA or an EST corresponding to the whole gene. Getting reliable cDNA sequence for this gene has been difficult due to the presence of potential recombinant sequences, a phenomenon reported previously for MHC gene families, where an amplified gene fragment can act as a PCR primer for another gene, leading to chimeric sequences. For example, cDNA 3 could be a recombinant sequence corresponding to both $B-D M B$ genes. This would reflect the close similarities already highlighted between $B$-DMB1 and $B-D M B 2$, and would concern especially the lowest transcriptional level gene, which seems to be $B-D M B 1$. Further studies on functions of the $B-D M B 1$ protein would be of interest because its features do not seem to fully match those of any MHC gene reported in mammals. But the $\mathrm{dN} / \mathrm{dS}$ values obtained for this gene could indicate pseudo-exons and/or ongoing pseudogeneization. Pseudogenes arising from a copy of a functional gene are quite common, in this case, it would be $B-D M B 2$.

Anyway, the three $B$-DM genes are expressed in immune related tissues, these observations are consistent with the ESTs reported in the databases, and phylogenetic analysis established the clustering of the $B-D M$ and the $D M$ genes, confirming the orthology of $B-D M$ genes with $D M$ genes.

Additionally, the phylogenetic analysis suggests that the $D M$ genes did separate from classical class II genes at an early stage, at least prior to the divergence of evolutionary lineages leading to mammals and birds, some 300 million years ago. This has been suggested before, in mammals (O'hUigin et al., 1998) and needed to be confirmed by the analysis of a non-mammalian vertebrate, such as the chicken.

It is also relevant to mention that whereas the two $D M B$ genes of the mouse are very similar, the chicken and the two bird species, the quail and turkey, for which we could find putative $D M$ sequences in databases, seemed to present two $D M B$ genes less similar, indicating a more ancient duplication.

\subsection{Genetic polymorphism of the B-DM molecules}

We resequenced the $B$-DM genes in 95 domestic chickens of different origins and in 25 red Junglefowl, five grey Junglefowl, and four Sri Lanka Junglefowl, then we added 17 sequences from the databases to our analysis. Even though polymorphisms are frequent in $B$-DM genes, they are not as numerous as those found in classical class II genes, as reported for mammals (Carrington et al., 1993; Hermel et al., 1995). But the chicken $B-D M A$ gene polymorphism differs from what has been described in humans for HLA-DMA, where only few polymorphisms have been described (Sanderson et al., 1994), with just 4 non-synonymous alleles reported in the IMGT/HLA database (Robinson et al., 2003). In comparison, 7 nonsynonymous alleles are reported in this database for HLA-DMB. Interestingly, all three non-synonymous SNPs reported for HLA$D M A$ are in the third exon, and $H L A-D M B$ have 4 non-synonymous SNPs in the second exon compared to only 2 in the third exon, which is similar to the distribution observed in chicken. Those observations concerning the distribution of the variations within the three $B-D M$, along with the results obtained in the $\mathrm{dN} / \mathrm{dS}$ analysis, show that the pattern of polymorphism observed for the genes are more likely to be the results of direct selective pressures, by opposition to an hitchhiking effect following the selection of other closely linked genes, such as the class I $B-F$ genes, proposed previously (Shiina et al., 2007).

The high sequence diversity in the MHC is linked to its important role in the host immune response and evidence of positive selection has been demonstrated recently in the chicken at those loci (Hosomichi et al., 2008). A preliminary analysis by Atkinson et al. (2001) concluded in the conservation of the putative implicated lateral faces of the $B$-DM molecules, implicating that, if those sites are conserved, then a classical class II molecule from any haplotype will bind a $B$-DM molecule of any other haplotype. This hypothesis is consistent with our results, showing an overall low level of polymorphism of the $B$-DM molecules and the conservation of specific domains. Therefore several amino acid residue variations reported in this study could result in functional differences for the encoded $B$-DM molecules, predicted to be key proteins of the exogenous antigen presentation pathway. Since, in chickens, the MHC $B$ region is strongly associated with resistance to some infectious diseases, any protein difference between serotypes is of importance.

Furthermore, the identification of a high number of haplotypes (124) especially under a non-recombinant model gives for the first 


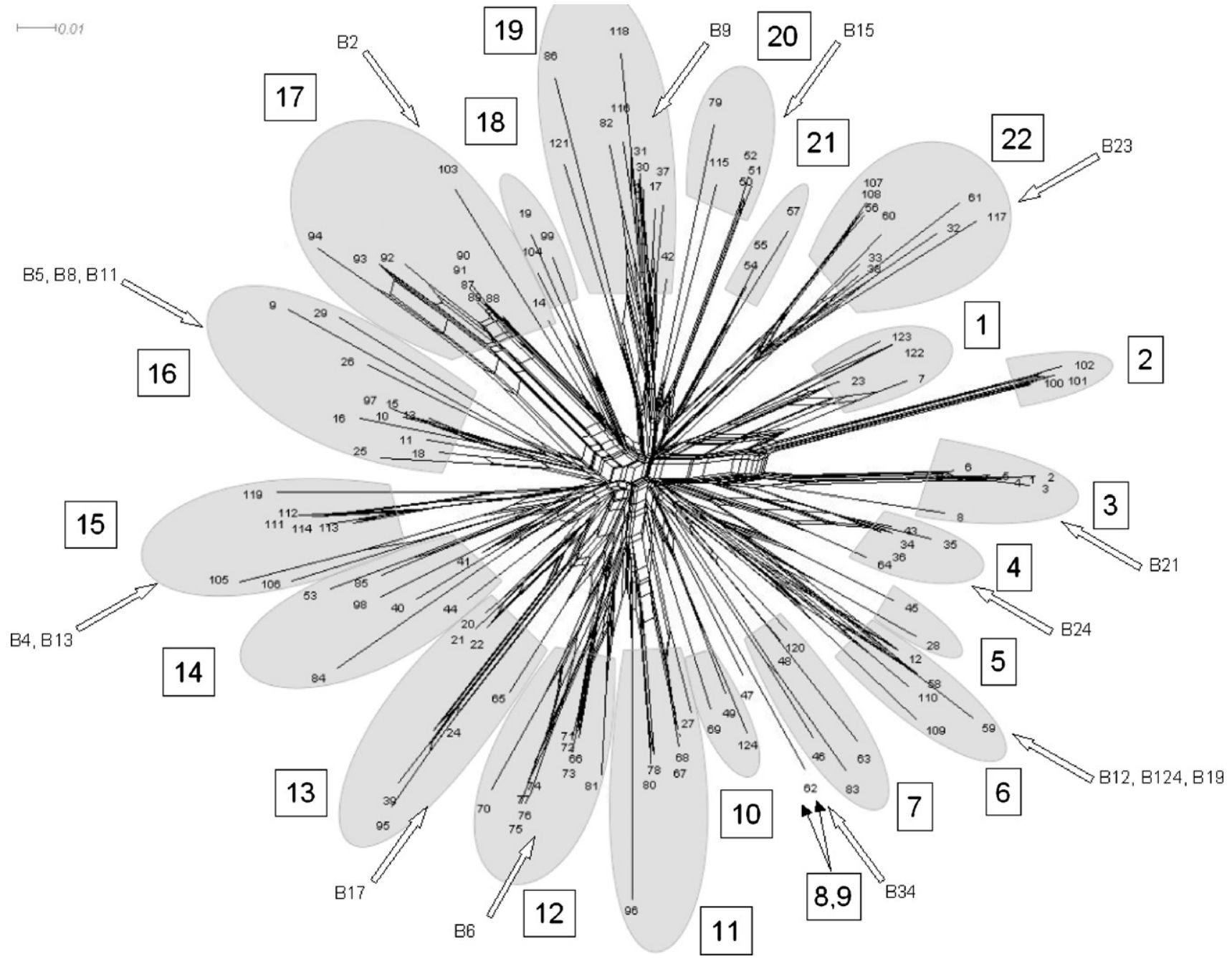

Fig. 5. NeighborNet network for the 124 B-DM haplotypes defined by 158 SNPs. The scale for branch lengths is indicated in the legend. The clusters are numbered and the presence of a haplotype corresponding to a serotype, previously defined by serology, is indicated by a white arrow.

time an overview of the worldwide MHC diversity for domestic chickens. Commercial breeds and especially local breeds showed a very high diversity. This leads to some loss of correspondence between the LEI0258 and GAB0001 allele sizes and the B-DM haplotypes, in contrast with reference white Leghorn lines.

Besides, in the network we reconstructed for the B-DM haplotypes, red Junglefowl haplotypes and to a lesser extent, grey Junglefowl and Sri-Lanka junglefowl haplotypes, can be found in 19 clusters (Supplementary Table 1). This observation could be related to the history of chicken domestication, which is characterised by multiple events of domestication in Asia, mainly from red Junglefowl (ICGSC, 2004) but also from other wild junglefowls (Eriksson et al., 2008). Therefore, the polymorphisms described between the different breeds and MHC $B$ haplotypes studied, are very valuable for taking a step towards understanding the evolutive dynamics of the $B$ region, in its class II part but also regarding the LEI0258 marker, located approximately $50 \mathrm{~kb}$ away, close to the class I region. Additionally, we were able to define 22 clusters grouping the reconstructed haplotypes, this can be taken as an indication of the existence of at least 22 relatively different MHC class II regions. If we consider that the most common serotypes were included in this study, and that only 12 of the 22 clusters could be associated with known serotypes, a large part of MHC diversity is lacking in serologically defined lines.

\section{Conclusion}

This study demonstrates the existence of three $D M$ genes in the chicken: $B-D M A, B-D M B 1$, and $B-D M B 2$. They are non-classical class II genes, homologous to the mammal $D M$ genes and are expressed in various immune related tissues. Their existence in the chicken is consistent with the hypothesis of their presence in the primordial MHC. The polymorphisms described between the different breeds and serotypes studied indicate a great diversity of the MHC in chicken breeds, in particular in local breeds, only partially represented by experimental lines.

\section{Acknowledgements}

We would like to thank Jean-Claude Fotsa (Institut de Recherche Agricole pour le Développement, Yaoundé, Cameroun), Valentine Yapi-Gnaore (Centre Nationale de Recherche Agronomique, Abidjan, Côte d'Ivoire), Issaka A.K. Youssao (Université d'Abomey-Calavi, Cotonou, Bénin), and Cheng Yu-Shin (Livestock Research Institute, Sinhua, Taiwan) for bird samples, and Boniface B. Kayang (University of Ghana, Legon, Ghana), Chi-Sheng Chang and Chih-Feng Chen (National Chung-Hsing University, Taichung, Taiwan) for bird samples and DNA extractions. We also thank Wendy Brandt-Williams (INRA, Jouy-en-Josas, France) for critical reading of the manuscript. 


\section{Appendix A. Supplementary data}

Supplementary data associated with this article can be found, in the online version, at doi:10.1016/j.molimm.2011.03.009.

\section{References}

Atkinson, D., Shaw, I., Jacob, J., Kaufman, J., 2001. DM gene polymorphisms: coevolution or coincidence? In: Proceedings of the Avian Immunology Research Group , Ithaca, 7-10 October 2000, pp. 163-165.

Altschul, S.F., Gish, W., Miller, W., Myers, E.W., Lipman, D.J., 1990. Basic local alignment search tool. J. Mol. Biol. 215, 403-410.

Bernot, A., Auffray, C., 1991. Primary structure and ontogeny of an avian CD3 transcript. Proc. Natl. Acad. Sci. U.S.A. 88, 2550-2554.

Briles, W.E., Briles, R.W., 1987. Genetics and classification of major histocompatibility complex antigens of the chicken. Poult. Sci. 66, 776-781.

Bryant, D., Moulton, V., 2004. Neighbor-net: an agglomerative method for the construction of phylogenetic networks. Mol. Biol. Evol. 21, 255-265.

Carrington, M., Yeager, M., Mann, D., 1993. Characterization of HLA-DMB polymorphism. Immunogenetics 38, 446-449.

Chang, C.M., Coville, J.L., Coquerelle, G., Gourichon, D., Oulmouden, A., TixierBoichard, M., 2006. Complete association between a retroviral insertion in the tyrosinase gene and the recessive white mutation in chickens. BMC Genomics $7,19$.

Cho, S., Attaya, M., Monaco, J.J., 1991. New class II-like genes in the murine MHC. Nature 353, 573-576.

Eriksson, J., Larson, G., Gunnarsson, U., Bed'hom, B., Tixier-Boichard, M., Strömstedt, L., Wright, D., Jungerius, A., Vereijken, A., Randi, E., Jensen, P., Andersson, L., 2008. Identification of the yellow skin gene reveals a hybrid origin of the domestic chicken. PLoS Genet. 4, e1000010.

Flot, J.F., 2010. Seqphase, a web tool for interconverting phase input/output files and fasta sequence alignments. Mol. Ecol. Resour. 10, 162-166.

Fulton, J.E., Juul-Madsen, H.R., Ashwell, C.M., McCarron, A.M., Arthur, J.A., O’Sullivan, N.P., Taylor Jr., R.L., 2006. Molecular genotype identification of the Gallus gallus major histocompatibility complex. Immunogenetics 58, 407-421.

Hermel, E., Yuan, J., Monaco, J.J., 1995. Characterization of polymorphism within the $\mathrm{H} 2-\mathrm{M}$ MHC class II loci. Immunogenetics 42, 136-142.

Hillel, J., Groenen, M.A., Tixier-Boichard, M., Korol, A.B., David, L., Kirzhner, V.M., Burke, T., Barre-Dirie, A., Crooijmans, R.P., Elo, K., Feldman, M.W., Freidlin, P.J., Mäki-Tanila, A., Oortwijn, M., Thomson, P., Vignal, A., Wimmers, K., Weigend, S., 2003. Biodiversity of 52 chicken populations assessed by microsatellite typing of DNA pools. Genet. Sel. Evol. 35, 533-557.

Hosomichi, K., Miller, M.M., Goto, R.M., Wang, Y., Suzuki, S., Kulski, J.K., Nishibori, M., Inoko, H., Hanzawa, K., Shiina, T., 2008. Contribution of mutation, recombination, and gene conversion to chicken MHC-B haplotype diversity. J. Immunol. 181, 3393-3399.

Huson, D.H., Bryant, D., 2006. Application of phylogenetic networks in evolutionary studies. Mol. Biol. Evol. 23, 254-267.

ICGSC (International Chicken Genome Sequencing Consortium), 2004. Sequence and comparative analysis of the chicken genome provide unique perspectives on vertebrate evolution. Nature 432, 695-716.

Kaufman, J., Milne, S., Göbel, T.W., Walker, B.A., Jacob, J.P., Auffray, C., Zoorob, R., Beck, S., 1999. The chicken B locus is a minimal essential major histocompatibility complex. Nature 28, 923-925.

Kelly, A.P., Monaco, J.J., Cho, S., Trowsdale, J., 1991. A new human HLA class II-related locus, DM. Nature 353, 571-573.

Kropshofer, H., Hämmerling, G.J., Vogt, A.B., 1999. The impact of the non-classical MHC proteins HLA-DM and HLA-DO on loading of MHC class II molecules. Immunol. Rev. 172, 267-278.
McConnell, S.K.J., Dawson, D.A., Wardle, A., Burke, T., 1999. The isolation and mapping of 19 tetranucleotide microsatellite markers in the chicken. Anim. Genet. 30, 183-189.

Miller, M.M., Bacon, L.D., Hala, K., Hunt, H.D., Ewald, S.J., Kaufman, J., Zoorob, R. Briles, W.E., 2004. 2004 Nomenclature for the chicken major histocompatibility (B and Y) complex. Immunogenetics 56, 261-279.

Minozzi, G., Parmentier, H.K., Nieuwland, M.G., Bed'hom, B., Minvielle, F., Gourichon, D., Pinard-van der Laan, M.H., 2007. Antibody responses to keyhole limpet hemocyanin, lipopolysaccharide, and Newcastle Disease virus vaccine in F2 and backcrosses of white Leghorn lines selected for two different immune response traits. Poult. Sci. 86, 1316-1322.

Morris, P., Shaman, J., Attaya, M., Amaya, M., Goodman, S., Bergman, C., Monaco, J.J., Mellins, E., 1994. An essential role for HLA-DM in antigen presentation by class II major histocompatibility molecules. Nature 368, 551-554.

Nei, M., Gojobori, T., 1986. Simple methods for estimating the numbers of synonymous and nonsynonymous nucleotide substitutions. Mol. Biol. Evol. 3, 418-426.

O'hUigin, C., Sültmann, H., Tichy, H., Murray, B.W., 1998. Isolation of mhc class II DMA and DMB cDNA sequences in a marsupial: the gray short-tailed opossum (Monodelphis domestica). J. Mol. Evol. 47, 578-585.

Rice, P., Longden, I., Bleasby, A., 2000. EMBOSS: the European molecular biology open software suite. Trends Genet. 16, 276-277.

Robinson, J., Waller, M.J., Parham, P., de Groot, N., Bontrop, R., Kennedy, L.J., Stoehr, P., Marsh, S.G.E., 2003. IMGT/HLA and IMGT/MHC: sequence databases for the study of the major histocompatibility complex. Nucleic Acids Res. 31,311-314.

Rozen, S., Skaletsky, H., 2000. Primer3 on the WWW for general users and for biologist programmers. Methods Mol. Biol. 132, 365-386.

Salomonsen, J., Marston, D., Avila, D., Bumstead, N., Johansson, B., Juul-Madsen, H., Olesen, G.D., Riegert, P., Skjødt, K., Vainio, O., Wiles, M.V., Kaufman, J., 2003. The properties of the single chicken MHC classical class II alpha chain (B-LA) gene indicate an ancient origin for the $\mathrm{DR} / \mathrm{E}$-like isotype of class II molecules. Immunogenetics 55, 605-614.

Sanderson, F., Powis, S.H., Kelly, A.P., Trowsdale, J., 1994. Limited polymorphism in HLA-DM does not involve the peptide binding groove. Immunogenetics 39, $56-58$.

Shiina, T., Briles, W.E., Goto, R.M., Hosomichi, K., Yanagiya, K., Shimizu, S., Inoko, H., Miller, M.M., 2007. Extended gene map reveals tripartite motif, C-type lectin, and Ig superfamily type genes within a subregion of the chicken MHC-B affecting infectious disease. J. Immunol. 178, 7162-7172.

Sloan, V.S., Cameron, P., Porter, G., Gammon, M., Amaya, M., Mellins, E., Zaller, D.M., 1995. Mediation by HLA-DM of dissociation of peptides from HLA-DR. Nature $375,802-806$

Staden, R., Beal, K.F., Bonfield, J.K., 2000. The Staden package, 1998. Methods Mol. Biol. 132, 115-130.

Stephens, M., Smith, N.J., Donnelly, P., 2001. A new statistical method for haplotype reconstruction from population data. Am. J. Hum. Genet. 68, 978-989.

Tamura, K., Dudley, J., Nei, M., Kumar, S., 2007. MEGA4: molecular evolutionary genetics analysis (MEGA) software version 4.0. Mol. Biol. Evol. 24, 1596-1599.

van den Elsen, P.J., Holling, T.M., Kuipers, H.F., van der Stoep, N., 2004. Transcriptional regulation of antigen presentation. Curr. Opin. Immunol. 16, 67-75.

Weckx, S., Del-Favero, J., Rademakers, R., Claes, L., Cruts, M., De Jonghe, P., Van Broeckhoven, C., De Rijk, P., 2005. novoSNP, a novel computational tool for sequence variation discovery. Genome Res. 15, 436-442.

Westerheide, S.D., Louis-Plence, P., Ping, D., He, X.F., Boss, J.M., 1997. HLA-DMA and HLA-DMB gene expression functions through the conserved S-X-Y region. J. Immunol. 158, 4812-4821.

Ye, H., Xu, F.Z. Yu, W.Y., 2009. The intracellular localization and oligomerization of chicken invariant chain with major histocompatibility complex class II subunits. Poult. Sci. 88, 1594-1600. 